\title{
ETL
}

International Conference on Research in Education, Teaching and Learning

Paris, France| November 2 -4, 2018

\section{The Effect of Big Book and Syllable Method on Language Skills}

\author{
Siti Aisyah \\ Universitas Terbuka
}

\begin{abstract}
This paper presents empirical data on the effect of reading methods and thinking skills toward language development in early childhood. The author investigated reading methods and thinking skills on the basis of causal relationships to positively enhance children's language development. To this end, the experimental group received direct treatment sessions, e.g., reading interventions for the children. The effect of the changes (or progress) in the experimental group was then measured against the control group. As the experiment dealt with multiple independent variables (reading methods and thinking skills) against one dependent variable (language skills), a 2x2 experimental design was used to see whether interactions existed between variables. The classification of the independent variables was based on action variable and moderator variable. While action variable referred to reading method (A) that included Big Book method (A1) and syllable method (A2), moderator variable referred to thinking skill (B) categorized by levels; high-level thinking skill (B1) and low-level thinking skill (B2). Anova tested for the difference in language development between the children exposed to Big Book method and those to syllable method, where the former performed better than the latter. Both methods were statistical significant, and yet Big Book was more effective than syllable method for fostering literacy skill in early childhood.
\end{abstract}

Keywords: Big Book Method, Syllables Method, and Language Skill. 
